ENTREPRENEURSHIP AND SUSTAINABILITY ISSUES

ISSN 2345-0282 (online) http://jssidoi.org/jesi/

2019 Volume 7 Number 1 (September)

http://doi.org/10.9770/jesi.2019.7.1(55)

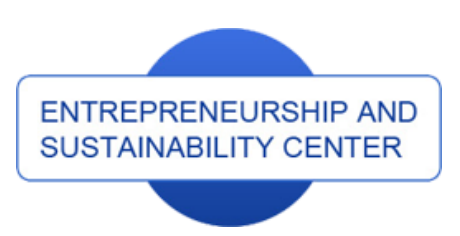

Publisher

http://jssidoi.org/esc/home

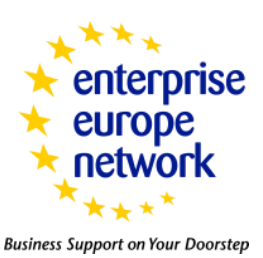

CASPA

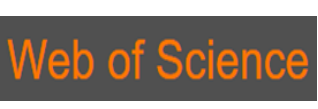

Clarivate
Analytics

\title{
PREVENTING REGIONAL SOCIAL AND ENVIRONMENTAL CONFLICTS DURING OIL PIPELINE CONSTRUCTION PROJECTS
}

\author{
Andrey Novoselov 1 , Irina Novoselova ${ }^{2}$, Ruslan Aliev ${ }^{3}$, Andrey Avramenko ${ }^{4}$ \\ ${ }^{1}$ Plekhanov Russian University of Economics, 36 Stremyanny Lane, Moscow, 117997, Russian Federation \\ ${ }^{2,3,4}$ Moscow State Institute of International Relations, (MGIMO University), 76 Prospect Vernadskogo, Moscow, 119454, \\ Russian Federation \\ E-mails: ${ }^{1}$ alnov2004@yandex.ru ; ${ }^{2}$ iunov2010@yandex.ru ; ${ }^{3}$ ecology@inno.mgimo.ru ; ${ }^{4}$ job_box2003@mail.ru
}

Received 25 March 2019; accepted 20 July 2019; published 30 September 2019

\begin{abstract}
The problem of constructing field pipelines from the oilfield to the main pipeline or an oil loading terminal is considered. Cost estimates for routes of field pipelines take into account the pipeline construction and operation costs, environmental accident pollution risks, compensations to local residents, and costs of compensatory projects to accommodate local interests. This helps to ensure that conflicts are avoided in the process of economic development of northern territories. A specific feature in evaluating the total costs is the use of fuzzy numbers. The authors' adaptation of the Shimbel-Otterman method is substantiated for choosing an optimum field pipeline route, whose adaptation involves the application of fuzzy cost estimates for individual segment options of the pipeline route. The proposed approach to the analysis of the resulting solution relies on the use of a confidence level function, which helps the decision-maker to identify the most viable field pipeline route option. A detailed algorithm for solving the problem is laid out, with a numerical example to prove the operational quality of the proposed method.
\end{abstract}

Keywords: pollution damage; environment; conflict; compensations to population; field pipeline; route; fuzzy estimate; confidence level; minimization of total costs

Reference to this paper should be made as follows: Novoselov, A.; Novoselova, I.; Aliev, R.; Avramenko, A. 2019. Preventing regional social and environmental conflicts during oil pipeline construction projects, Entrepreneurship and Sustainability Issues 7(1): 773-785. http://doi.org/10.9770/jesi.2019.7.1(55)

JEL Classifications: Q01, Q32

\section{Introduction}

Oil production in underdeveloped areas of the world, including such areas in Russia, inevitably causes adverse environmental impact, destruction of animal migration routes, deterioration of hunting lands, and depletion of fish populations in rivers (Guri et al. 2013). Alongside oil production, a serious negative contributor is oil transportation via field pipelines from the field being developed to a main pipeline or a sea or river terminal. Route planning options for building such pipelines should take into account the following factors: capital 


\section{ENTREPRENEURSHIP AND SUSTAINABILITY ISSUES}

ISSN 2345-0282 (online) http://jssidoi.org/jesi/

2019 Volume 7 Number 1 (September)

http://doi.org/10.9770/jesi.2019.7.1(55)

expenditure in construction; operating expenses; economic estimates of potential environmental damage caused by accidents on the pipeline (Nriagu et al. 2016); compensations to local population in the area of pipeline construction to eliminate socio-environmental conflicts; implementation costs of compensatory project to accommodate local interests (O'Faircheallaigh 2009; Shvetsova et al. 2018). As long as several options may be available for planning solutions in field pipeline construction, the choice of the best option should include a solution of the problem of minimizing the total project costs of oil transportation, i.e., the problem of identifying the optimum pipeline route.

\section{Problem setting and analysis of approaches to the solution}

To identify an optimum construction option for a field pipeline, a pipeline diagram should be charted, including options for individual segments $(i j)$, linked into a single network $G$, i.e. $(i j) \in G$. Network $G$ includes all laying options of the planned field pipeline. The optimum field pipeline route will be found in this proposed network, taking into account the lowest cumulative costs. The amount of investment $D_{(i j)}$ and annual operating costs $S_{(i j)}$ are determined based on feasibility studies for each of the segments $(i j) \in G$ individually.

The annual economic estimate for accident-related damage $U_{(i j)}$ is based on an analysis of natural risks, such as seismic activity in the area measured by the MSK-64 scale. Calculations also include technical factors associated with the external corrosion of the piping, mechanical damage, defects of construction and installation, as well as defects of piping. Apart from that, assessments of potential damage from accidents on a particular segment of the pipeline should take into account several criteria: occurrence of Specially Protected Natural Reservation areas of either federal or regional significance within the corridor of the pipeline; crossing into the optimal habitat of rare, "Red Book" or economically valuable species of plants and animals; crossing into the group I forestry; crossing rivers designated as the first fishery category and significant spawning routes; proportion of the route segments affecting the least disturbed ecosystems outside specially protected areas, which represent considerable importance for preserving biodiversity (Porfiryev, Tulupov 2017).

The aggregate assessment of the annual accident risk on the pipeline segment $(i j)$ is calculated according to the equation:

$$
R_{(i j)}=U_{(i j)} \times l \times L_{(i j)},
$$

$U_{(i j)}$ - economic estimate of environmental pollution damage taking into account the specifics of the area for segment $(i j) \in G$ of the field pipeline, thousand euro;

$l$-accident risk on the pipelines in the region per $1 \mathrm{~km}$ per year, fractions;

$L_{(i j)}$ - length of segment $(i j) \in G$ of the planned field pipeline, km.

As long as the economic estimate of environmental pollution damage and the relative accident rate (Fetisov et al. 2016) are defined as intervals characterised by a min and a max and an anticipated value (av), then the value of risk according to equation (1) is determined by the three components: $\hat{R}_{(i j)}=\left(R_{(i j)}^{\min } ; R_{(i j)}^{a v} ; R_{(i j)}^{\max }\right)$. Such presentation of the above indicators corresponds to fuzzy (triangular) numbers (Uzhga-Rebrov, Kuleshova 2015). Each of the three components of the number has a respective confidence level $\mu(R)$, wherein $\mu\left(R^{\min }\right)=0 ; \mu\left(R^{a v}\right)=1 ; \mu\left(R^{\max }\right)=0$. Fuzzy numbers can be represented in a chart, e.g. for number $\hat{R}=(4 ; 8 ; 10)$ the resulting presentation is as follows in Fig. 1. 


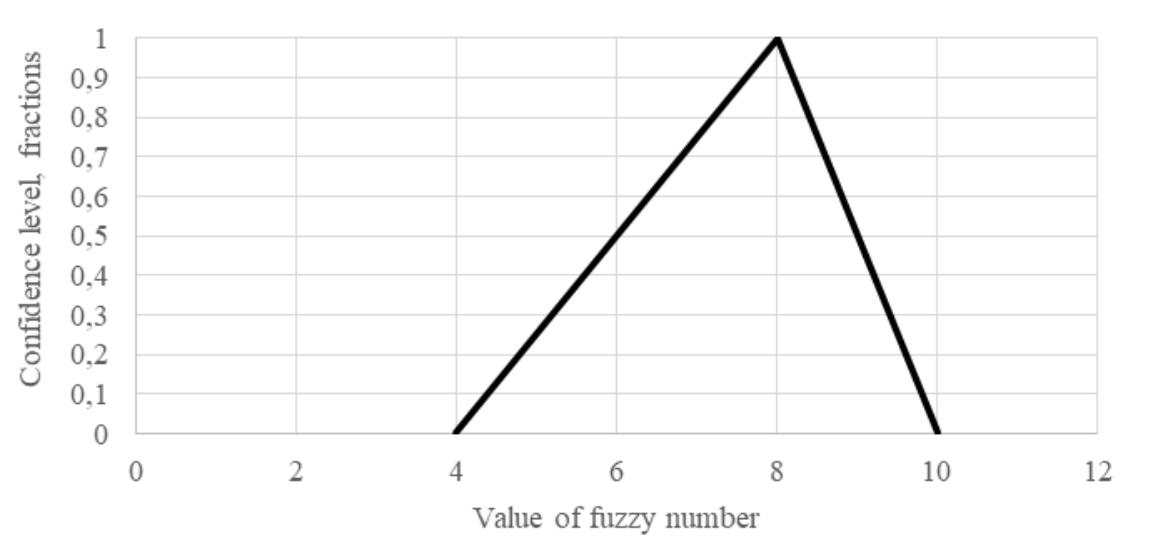

Fig.1. Graphic representation of triangular number $\hat{R}=(4 ; 8 ; 10)$

Sociocultural risks (Tulupov 2017) represent the negative effects of the pipeline for local social and cultural values during the construction and operation of the pipeline. The assessment of sociocultural risks should take into account the following aspects: line passage in populated indigenous ancestral settlement areas; crossing into the areas of traditional natural resource exploitation and traditional local economic activities; pipeline effects for traditional lifestyles; pipeline construction effects for cultural and religious heritage sites and public health. The above risks result in the payment of compensations linked to lost benefits and damage caused to locals and spending by the oil producer on projects to eliminate conflict with the population. Cost estimates associated with compensation payments and such projects for year $t$ are determined for each segment $(i j) \in G$ of the planned field pipeline. We shall designate these costs $\hat{P}_{t(i j)}=\left(P_{t(i j)}^{\min } ; P_{t(i j)}^{a v} ; P_{t(i j)}^{\max }\right)$.

Route optimization for a field pipeline from the production site to the main pipeline is supposed to minimize capital and operating costs, mitigate the above-mentioned risks and bring down compensation payments. A clear optimization criterion including the above components should be developed and an algorithm has to be worked out to identify an optimum pipeline passage route in the described outlook

\section{Developed problem-solving approach}

The selection of an optimum pipeline passage route is operated using an oriented graph $G$ without reverse arcs. Each arc (ij) corresponds to a pipeline segment followed by alternative next segments or the final pipeline destination point. As long as each of the pipeline segments ( $i j)$ is associated with certain levels of construction and operating costs, compensation payments to the population and damages in case of accidents, these costs should be considered dynamically for the period of construction and operation of the pipeline. For that, the annual figures should be added up taking into account the time factor, i.e., using the discounting (present value) factor (Novoselova, Novoselov 2016). As the total costs correspond to the pipeline segment ( $\mathrm{ij}$ ), we shall designate them as $E_{(i j)}$.

Total costs for arc $(i j)$ are calculated according to the equation as a triangular number:

$$
\hat{E}_{(i j)}=\sum_{t=T_{1}}^{T_{2}}\left(S_{t(i j)}+\hat{R}_{t(i j)}\right)(1+r)^{1-t}+\sum_{t=1}^{T_{0}} D_{t(i j)}(1+r)^{1-t}+\sum_{t=1}^{T_{1}} \hat{P}_{t(i j)}(1+r)^{1-t}
$$


where $S_{t(i j)}$ is operating costs for pipeline segment $(i j) \in G$ for year $t$;

$\hat{R}_{t(i j)}$ - fuzzy estimate of the risk of environmental pollution damage in case of accidents caused by technology or natural factors during the operation of pipeline segment $(i j) \in G$ for year $t$;

$D_{t(i j)}$-investment in the construction of pipeline segment $(i j) \in G$ for year $t$;

$\hat{P}_{t(i j)}$ - fuzzy estimate of compensation payments to the population and spending on conflict elimination projects related to the construction and operation of pipeline segment $(i j) \in G$ for year $t$;

$t$ - current year;

$\left(1,2 \ldots T_{0}\right)$ - construction period of pipeline segment $(i j)$;

$\left(T_{0}+1, \ldots T_{1}\right)$ - operation period of pipeline segment $(i j)$.

For identifying a construction solution minimizing total costs for a field pipeline $L=\{1, \ldots n\}$ linking the oil field (the start event in the graph of options of field pipeline construction with the corresponding value 1) to the final destination - a main pipeline or a loading terminal (the finish event in the graph of options of field pipeline construction with the corresponding value $n$ ), one of the following methods (Akhtar et al. 2016) is proposed: the Floyd-Warshall algorithm; the Bellman-Ford algorithm; Dijkstra's algorithm; Johnson's algorithm; Shimbel's algorithm. The application of the latter method is based on the adjacency matrix of the analysed pipeline passage graph. A distinctive feature of the Shimbel's algorithm is the step-by-step calculation of total cost estimates for pipeline fragments comprising firstly two segments, then three segments and more. This method can be conveniently combined with Otterman's routing method (Schrijver 2012) to eventually arrive at an optimum choice corresponding to the lowest-cost option identified by Shimbel's method. Importantly, the amount of computation under the method is less dependent on the complexity of the graph of alternative routes $G$. Moreover, the Shimbel-Otterman method is usable for the software application. This warranted the selection of the ShimbelOtterman method for the set problem.

While the total cost estimates for each segment of the pipeline route in the discussed problem calculated according to (2) are represented as fuzzy numbers $\hat{E}_{(i j)}=\left(E_{(i j)}^{\min } ; E_{(i j)}^{a v} ; E_{(i j)}^{\max }\right)$, the application of the ShimbelOtterman method $L=\{1, \ldots n\}$ for routing problem with fuzzy data (Ahmed, Kilic 2019) required an adjustment.

The proposed adapted algorithm renders a step-by-step selection of an optimum pipeline route for the minimum $E_{(i j)}^{\min }$, anticipated $E_{(i j)}^{a v}$ and maximum $E_{(i j)}^{\max }$ values of the total costs for each segment of the route. For convenience, we shall assume $\mu$ equals "min" or "av" or "max", i.e., calculations are made for $E_{(i j)}^{\mu}$. The output is three optimum routes with corresponding construction and operation costs and compensations to the population $F^{\mu}: F^{\min }, F^{a v}, F^{\max }$. The resulting fuzzy estimate of costs $F=\left(F^{\min } ; F^{a v} ; F^{\max }\right)$ is further supplied with a corresponding calculation of the level of confidence in the attainment of the respective result, which helps to arrive at a conclusive pipeline route choice. 


\section{Detailed problem-solving algorithm}

The algorithm consists of the following steps.

Step 1. Calculations of an estimate of total costs for $\mu$.

Step 2. Adjacency matrix $A$ is built, showing total cost estimates $E_{(i j)}^{\mu}$ for the existing arcs, where the respective values are predetermined according to (1):

$$
A_{i j}=\left\{\begin{array}{l}
E_{(i j)^{r}}^{\mu} \quad \forall(i j) \in G \\
0, \quad \text { in the contrary case }
\end{array}\right.
$$

Step 3. Assigning $B=A ; p=1$

Step 4. Calculation of the matrix $C^{p}$ of the sums of weights for the nodes of all paths containing two arcs according to the rules (3). Elements of matrix $C$ are calculated according to the equation:

$C_{i j}^{p}=\left\{\begin{array}{l}\min _{k=1,2_{s} n n}\left\{a_{k j}+b_{i k}\right\}, \text { for } a_{k j}>0 \text { and } b_{i k}>0 \\ 0, \quad \text { if all } a_{k j} \text { and } b_{i k}=0\end{array}\right.$

Step 5. Building the routing matrix $T^{p}$ showing the preceding node for each node along the way represented in the matrix columns according to the rule:

$T_{i j}^{p}=\left\{\begin{array}{l}k^{*} \text { based on } \min _{k=1,2, n}\left\{C_{i j}^{p}\right\}, \text { where there exists } C_{i j}^{p}>0 \\ 0, \quad \text { if all } C_{i j}^{p}=0\end{array}\right.$

Step 6. Test: is the matrix $C^{p}$ comprising only zeros? If yes, go to step 8 , otherwise, step 7.

Step 7. Assigning $B=A ; p=p+1$; go to step 3 .

Step 8. Determining the minimum weight for the best pipeline construction option:

$$
F^{\mu}=\min _{l=1,2, \ldots p}\left\{C_{1 n}^{p}\right\}
$$

Step 9. Building the optimum route $L^{*}=\{1, \ldots n\}$ based on the first lines of the routing matrix $C^{l}, l=1,2, . . p^{*}$. End of calculation for the considered fuzzy estimate of the total costs of the pipeline by the segments: $F=\left(F^{\min } ; F^{a v} ; F^{\max }\right)$.

The described algorithm is repeated for each of the border values of the fuzzy estimate of the total costs of pipeline construction: Thus, optimum routing options are determined according to the minimum total cost criterion (2).

Different methods can be used to analyse the fuzzy result arrived at, e.g. see (Mazarbhuiya 2016). A confidence function is further built based on the results achieved for the optimum total cost values: 
Step 1. Calculation of the interim value $\alpha$ given the variation of $g$ from $F^{\text {min }}$ to $F^{\text {max }}$ with an interval $\Delta=\frac{F^{\max }-F^{\min }}{N}$ :

$$
\alpha= \begin{cases}\frac{F^{\max }-g}{F^{\max }-F^{a v}}, & F^{a v} \leq G \leq F^{\max } \\ \frac{g-F^{\min }}{F^{a v}-F^{\min }}, & F^{\min } \leq G<F^{a v}\end{cases}
$$

Step 2. Calculation of the interim value $\beta$ given the variation of $g$ from $F^{\min }$ to $F^{\max }$ with a preset a priori interval $\Delta$ :

$$
R=\frac{F^{\max }-g}{F^{\max }-F^{\min }}, \quad F^{\min } \leq g<F^{\max }
$$

Step 3. Calculation of the values of the confidence function $k(g)$ given the variation of $G$ from $F^{\min }$ to $F^{\max }$ with a preset a priori interval $\Delta$ :

$$
k(G)=\left\{\begin{array}{c}
\beta\left(1+\frac{1-\alpha}{\alpha} \ln (1-\alpha)\right), F^{\min } \leq g<F^{a v} \\
1-(1-\beta)\left(1+\frac{1-\alpha}{\alpha} \ln (1-\alpha)\right), F^{a v} \leq g<F^{\max } \\
1, g=F^{\max }
\end{array}\right.
$$

Each segment of the confidence function has a corresponding optimum pipeline option with minimum total costs, which means a route can be selected for the required upper limit of the confidence level.

\section{Example of charting an optimum route of field pipeline}

The segments for charting an optimum pipeline route and the corresponding economic parameters are laid out in Table 1. 
Table 1. The source data for the formation of the optimal variant of the oil pipeline

\begin{tabular}{|c|c|c|c|c|c|}
\hline \multirow{2}{*}{$\begin{array}{c}\text { Route segment } \\
\text { option (i,j) }\end{array}$} & \multicolumn{5}{|c|}{ Discounted values, million euro } \\
\cline { 2 - 6 } & Investment & Current costs & $\begin{array}{c}\text { Fuzzy estimate of } \\
\text { accident risk }\end{array}$ & $\begin{array}{c}\text { Fuzzy estimates for } \\
\text { compensation payments } \\
\text { and costs of compensatory } \\
\text { projects }\end{array}$ & $\begin{array}{c}\text { Fuzzy total estimate } \\
\text { for a route segment }\end{array}$ \\
\hline$(1,2)$ & 1.2 & 0.7 & $(0,8 ; 1,2 ; 1,4)$ & $(0,6 ; 0,7 ; 0,8)$ & $(3,3 ; 3,8 ; 4,1)$ \\
\hline$(1,3)$ & 1.4 & 0.6 & $(0,4 ; 0,8 ; 0,9)$ & $(0,2 ; 0,3 ; 0,5)$ & $(2,6 ; 3,1 ; 3,4)$ \\
\hline$(2,3)$ & 1.0 & 0.5 & $(1,2 ; 1,4 ; 1,5)$ & $(0,5 ; 0,6 ; 0,8)$ & $(3,2 ; 3,5 ; 3,8)$ \\
\hline$(2,4)$ & 0.8 & 0.5 & $(0,5 ; 0,6 ; 0,8)$ & $(0,8 ; 0,9 ; 1,1)$ & $(2,6 ; 2,8 ; 3,2)$ \\
\hline$(3,6)$ & 6.7 & 1.6 & $(0,7 ; 0,9 ; 1,1)$ & $(0,3 ; 0,5 ; 0,7)$ & $(9,3 ; 10,7 ; 11,7)$ \\
\hline$(4,5)$ & 0.7 & 0.5 & $(0,8 ; 0,9 ; 1,2)$ & $(0,5 ; 0,8 ; 0,9)$ & $(2,5 ; 2,9 ; 3,3)$ \\
\hline$(4,6)$ & 2.1 & 1.8 & $(0,6 ; 0,8 ; 0,9)$ & $(0,2 ; 0,5 ; 0,7)$ & $(4,7 ; 5,2 ; 5,5)$ \\
\hline$(5,6)$ & 1.2 & 0.4 & $(0,4 ; 0,7 ; 0,9)$ & $(0,1 ; 0,3 ; 0,6)$ & $(2,1 ; 3,7 ; 4,2)$ \\
\hline
\end{tabular}

Based on individual segments, a graph of alternative routes running from node $i=1$ corresponding to the oil field to node $j=6$ representing the main pipeline can be easily built (Fig. 2). The arcs are marked with the corresponding fuzzy estimates of the total costs of construction and operation including damages and compensation payments to the population.

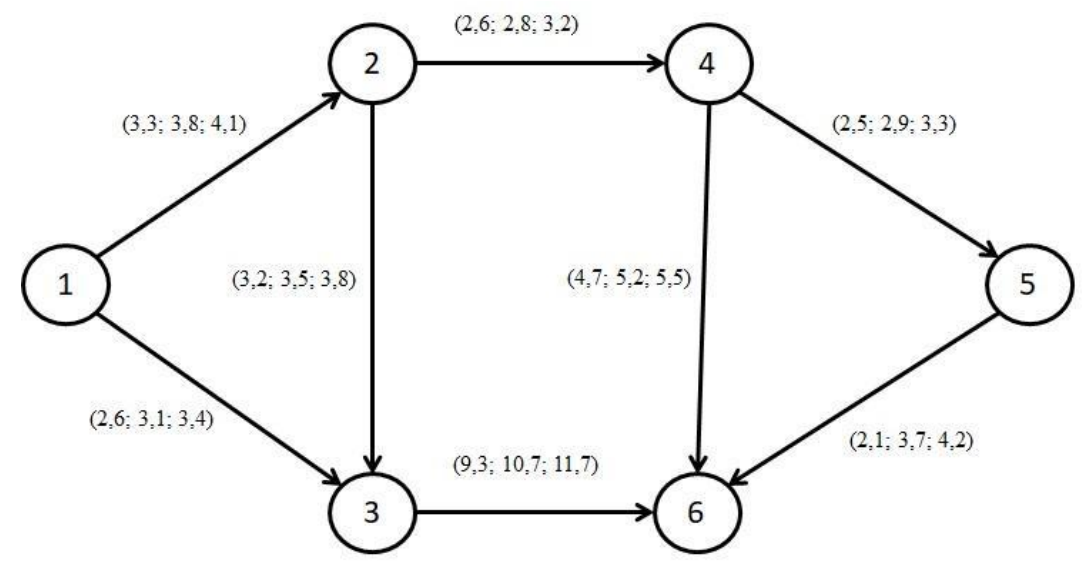

Fig.2. Route options for field pipeline

Consider the route options represented by the adjacency matrix (Table 2) showing the minimum total costs of implementation of field pipeline segments.

Table 2. Inputs for selecting optimum construction option based on minimum total costs

\begin{tabular}{|c|c|c|c|c|c|c|}
\hline \multirow{3}{*}{$i$} & \multicolumn{6}{|c|}{ Total minimum costs for the pipeline segment running from $i$ to $j$, million euro } \\
\cline { 2 - 7 } & 1 & 2 & 3 & 4 & 5 & 6 \\
\cline { 2 - 7 } 1 & 0 & 3.3 & 2.6 & 0 & 0 & 0 \\
\hline 2 & 0 & 0 & 3.2 & 2.6 & 0 & 0 \\
\hline 3 & 0 & 0 & 0 & 0 & 0 & 9.3 \\
\hline 4 & 0 & 0 & 0 & 0 & 2.5 & 4.7 \\
\hline 5 & 0 & 0 & 0 & 0 & 0 & 2.1 \\
\hline 6 & 0 & 0 & 0 & 0 & 0 & 0 \\
\hline
\end{tabular}

Elements of Table 3 are calculated according to equation (5). E.g. to calculate the elements of the matrix $(1,3)$, refer to line 1 and column 3 of the input data (Table 2): 


$$
C_{1,3}^{1}=\min \{0+2,6 ; 3,3+3,2 ; 0+0 ; 0+0 ; 0+0 ; 0+0\}=6,5
$$

All other values in Table 3 are calculated accordingly.

Table 4 shows the numbers of the nodes shaping the last fragment of the route. E.g., Table 3 renders routes consisting of two segments. The two-segment minimum route from node $(i=1)$ to node $i=3$ runs through node 2 . This can be established by selecting a minimum nonzero element according to equation (6). Thus, "2" is indicated at the intersection of line 1 and column 3 in the routing matrix.

Table 3. Optimum pipeline fragment options, two segment solutions

\begin{tabular}{|c|c|c|c|c|c|c|}
\hline \multirow{2}{*}{$i$} & \multicolumn{7}{|c|}{ Total costs on paths to nodes $j$, million euro } \\
\cline { 2 - 7 } & 1 & 2 & 3 & 4 & 5 & 6 \\
\hline 1 & 0.00 & 0.00 & 6.50 & 5.90 & 0.00 & 11.90 \\
\hline 2 & 0.00 & 0.00 & 0.00 & 0.00 & 5.10 & 7.30 \\
\hline 3 & 0.00 & 0.00 & 0.00 & 0.00 & 0.00 & 0.00 \\
\hline 4 & 0.00 & 0.00 & 0.00 & 0.00 & 0.00 & 4.60 \\
\hline 5 & 0.00 & 0.00 & 0.00 & 0.00 & 0.00 & 0.00 \\
\hline 6 & 0.00 & 0.00 & 0.00 & 0.00 & 0.00 & 0.00 \\
\hline
\end{tabular}

Table 4. Routing of identified pipeline fragments, two segments

\begin{tabular}{|c|c|c|c|c|c|c|}
\hline \multirow{2}{*}{$i$} & \multicolumn{7}{|c|}{ Path to node $j$} \\
\cline { 2 - 7 } & 1 & 2 & 3 & 4 & 5 & 6 \\
\hline 1 & 0 & 0 & 2 & 2 & 0 & 3 \\
\hline 2 & 0 & 0 & 0 & 0 & 4 & 4 \\
\hline 3 & 0 & 0 & 0 & 0 & 0 & 0 \\
\hline 4 & 0 & 0 & 0 & 0 & 0 & 5 \\
\hline 5 & 0 & 0 & 0 & 0 & 0 & 0 \\
\hline 6 & 0 & 0 & 0 & 0 & 0 & 0 \\
\hline
\end{tabular}

Table 4 shows the numbers of the nodes shaping the last fragment of the route. E.g., Table 3 renders routes consisting of two segments. The two-segment minimum route from node $(i=1)$ to node $i=3$ runs through node 2 . This is established by selecting a minimum nonzero element according to equation (6). Thus, "2" is indicated at the intersection of line 1 and column 3 in the routing matrix.

In this problem, a route needs to be selected, running from the field $(i=1)$ to the main pipeline $(i=6)$. As can be seen from Table 3, there is such route consisting of two fragments and its total weight equals 11.9 million euro. According to Table 4, the route runs through nodes 1,3 and 6, i.e. $L=\{1,3,6\}$.

Further calculation is warranted since the minimum number of fragments in the route does not guarantee a minimum total weight. Therefore, a new matrix is built further, showing minimum total weight estimates for all routes comprising three segments (Tables 5,6).

Table 5. Optimum pipeline fragment options, three segments

\begin{tabular}{|c|c|c|c|c|c|r|}
\hline \multirow{2}{*}{$i$} & \multicolumn{6}{|c|}{ Total costs on paths to nodes $j$, million euro } \\
\cline { 2 - 7 } & 1 & 2 & 3 & 4 & 5 & 6 \\
\hline 1 & 0.00 & 0.00 & 0.00 & 0.00 & 8.40 & 10.60 \\
\hline 2 & 0.00 & 0.00 & 0.00 & 0.00 & 0.00 & 7.20 \\
\hline 3 & 0.00 & 0.00 & 0.00 & 0.00 & 0.00 & 0.00 \\
\hline 4 & 0.00 & 0.00 & 0.00 & 0.00 & 0.00 & 0.00 \\
\hline 5 & 0.00 & 0.00 & 0.00 & 0.00 & 0.00 & 0.00 \\
\hline 6 & 0.00 & 0.00 & 0.00 & 0.00 & 0.00 & 0.00 \\
\hline
\end{tabular}

Table 6. Routing of identified pipeline fragments, three segments

\begin{tabular}{|c|c|c|c|c|c|c|}
\hline \multirow{2}{*}{$i$} & \multicolumn{7}{|c|}{ Path to node $j$} \\
\cline { 2 - 7 } & 1 & 2 & 3 & 4 & 5 & 6 \\
\hline 1 & 0 & 0 & 0 & 0 & 4 & 4 \\
\hline 2 & 0 & 0 & 0 & 0 & 0 & 5 \\
\hline 3 & 0 & 0 & 0 & 0 & 0 & 0 \\
\hline 4 & 0 & 0 & 0 & 0 & 0 & 0 \\
\hline 5 & 0 & 0 & 0 & 0 & 0 & 0 \\
\hline 6 & 0 & 0 & 0 & 0 & 0 & 0 \\
\hline
\end{tabular}


The number of the node with the lowest total weight is further established. For line 1 and column 6 , the respective node is the fourth node, therefore, "4" is indicated at the intersection of line 1 and column 6.

Tables 7 and 8 are calculated similarly for routes comprising four pipeline fragments.

Table 7. Optimum pipeline fragment options, four segments

\begin{tabular}{|c|c|c|c|c|c|c|}
\hline \multirow{2}{*}{$i$} & \multicolumn{6}{|c|}{ Total costs on paths to nodes $j$, million euro } \\
\cline { 2 - 7 } & 1 & 2 & 3 & 4 & 5 & 6 \\
\hline 1 & 0.00 & 0.00 & 0.00 & 0.00 & 0.00 & 10.50 \\
\hline 2 & 0.00 & 0.00 & 0.00 & 0.00 & 0.00 & 0.00 \\
\hline 3 & 0.00 & 0.00 & 0.00 & 0.00 & 0.00 & 0.00 \\
\hline 4 & 0.00 & 0.00 & 0.00 & 0.00 & 0.00 & 0.00 \\
\hline 5 & 0.00 & 0.00 & 0.00 & 0.00 & 0.00 & 0.00 \\
\hline 6 & 0.00 & 0.00 & 0.00 & 0.00 & 0.00 & 0.00 \\
\hline
\end{tabular}

Table 8. Routing of identified pipeline fragments, four segments

Further calculations produce zero matrices. Thus, the results identified in Tables 7, 8 are final.

The resulting options are further used to identify a route with minimum weight. Minimum value in Tables 3, 5, 7 is established in line 1 and column 6. The minimum value, which is 10.5 million euro, is found in Table 7, therefore, the optimum route consists of four arcs (pipeline segments). To establish the sequence of nodes in the route, refer to the routing matrix corresponding to the table that produced the minimum value, i.e., Table 8 . The intersection of line 1 and column 6 has "5", therefore, node 6 is approached via node 5. Refer to the previous routing

matrix (Table 6). The intersection of line 1 and column 4 has "4", therefore, the path to node 5 runs via node 4. The intersection of line 1 and column 4 in Table 4 has "2", therefore, route segment $(2,4)$ is selected. There is no further routing matrix, thus, segment $(1,2)$ is selected. Therefore, the optimum oil pipeline choice runs along route $L=\{1-2-4-5-6\}$, which produces the optimum level of costs of 10.5 million euro based on the minimum total cost estimates for route segment options.

The described algorithm is further applied to produce an optimum route for the average (av) and maximum (max) values of the total cost estimates for pipeline segment options. Calculation results are laid out in Table 9.

Table 9. Results of selection of optimum pipeline route based on the components of fuzzy total cost estimates for segment options

\begin{tabular}{|l|c|c|}
\hline $\begin{array}{l}\text { Calculation approach based on the components of fuzzy } \\
\text { estimates of costs for route segment options }\end{array}$ & Optimum route & $\begin{array}{c}\text { Present value of total costs, } \\
\text { million euro }\end{array}$ \\
\hline 1. Based on minimum estimates, $E_{(i j)}^{\min }$ & $L=\{1-2-4-5-6\}$ & 10.5 \\
\hline 2. Based on average estimates, $E_{(i j)}^{a v}$ & $L=\{1-2-4-6\}$ & 11.8 \\
\hline 3. Based on maximum estimates, $E_{(i j)}^{\max }$ & $L=\{1-2-4-6\}$ & 12.8 \\
\hline
\end{tabular}


The resulting estimates of total costs for optimum routes from the last column of Table 9 are the components of a fuzzy number, for which further analysis needs to be conducted based on rendering a confidence function. Assume the number of cases analysed at $N=10$. Then the interval of search is $\Delta=\frac{F^{\max }-F^{\min }}{N}=\frac{12.8-10.5}{10}=2.33$ million euro. The identified interval is used to walk through the levels of total costs from the minimum to the maximum value (first column of Table 10). The remaining items in the table are determined according to (8-10).

Table 10. Calculation of data for building confidence function

\begin{tabular}{|c|c|c|c|}
\hline \multirow{2}{*}{$g$, million euro } & \multicolumn{2}{|c|}{ Interim parameters } & \multirow{2}{*}{ Confidence level estimate $k(g)$, proportions } \\
\cline { 2 - 3 } & $\alpha$ & $\beta$ & 0.00 \\
\hline 10.50 & 0.00 & 0.10 & 0.01 \\
\hline 10.73 & 0.18 & 0.20 & 0.04 \\
\hline 10.96 & 0.35 & 0.30 & 0.10 \\
\hline 11.19 & 0.53 & 0.40 & 0.20 \\
\hline 11.65 & 0.71 & 0.50 & 0.36 \\
\hline 11.88 & 0.88 & 0.60 & 0.69 \\
\hline 12.11 & 0.92 & 0.70 & 0.86 \\
\hline 12.34 & 0.69 & 0.80 & 0.94 \\
\hline 12.57 & 0.46 & 0.90 & 0.99 \\
\hline
\end{tabular}

Based on the confidence level assessment $k(g)$ laid out in the last column of Table 10, a chart of the confidence function is built (Fig. 3).

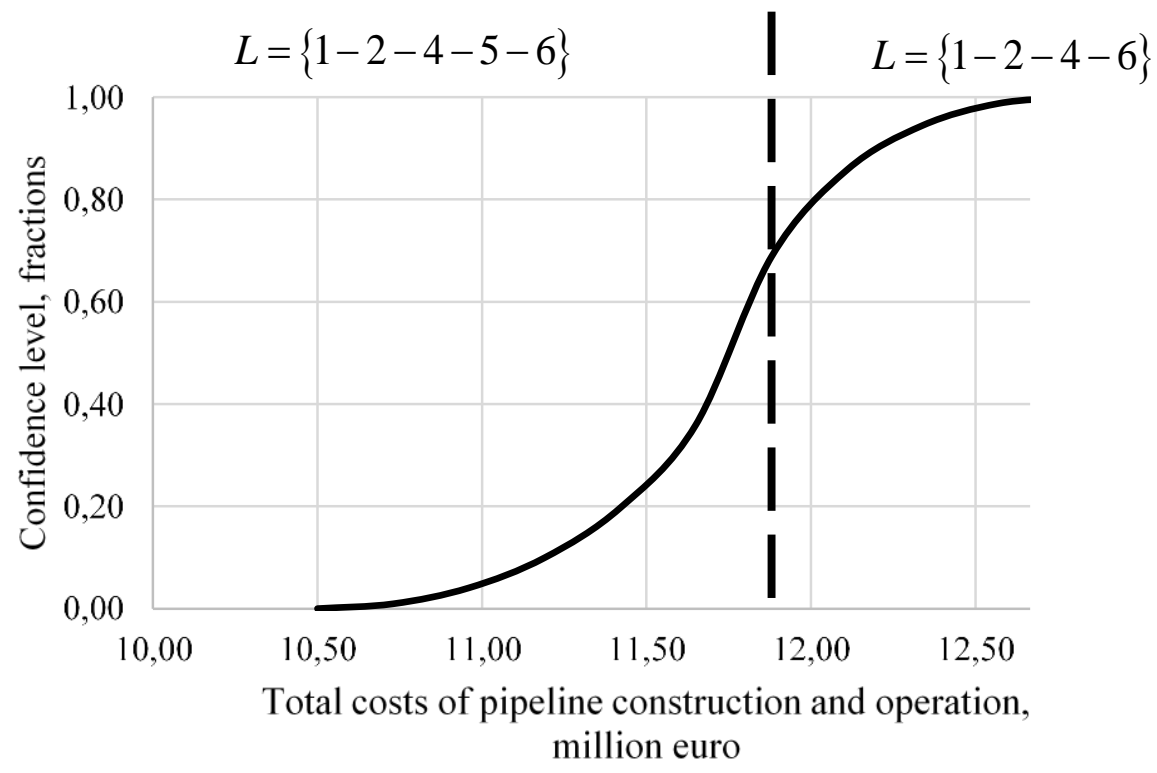

Fig.3. Confidence function charted for optimum pipeline routes

The dashed line in Fig. 3 runs through the average component of the fuzzy estimate of the present value of total costs, 11.8 million euro, with the corresponding confidence level of 0.67 . Where confidence level is lower than 0.67 , the route option $L=\{1-2-4-5-6\}$ should be chosen, otherwise, option $L=\{1-2-4-6\}$. 


\section{ENTREPRENEURSHIP AND SUSTAINABILITY ISSUES}

ISSN 2345-0282 (online) http://jssidoi.org/jesi/

2019 Volume 7 Number 1 (September)

http://doi.org/10.9770/jesi.2019.7.1(55)

\section{Results and discussion of the application of the method}

This study was completed to advance the development of the basic methods of analysis and conflict resolution related to environmental issues addressed earlier (Novoselov et al. 2016). The probabilistic approach to estimating the environmental pollution damage as described in this paper is consistent with modern methods (Chhabra et al. 2018). Meanwhile, there appears an opportunity to arrive at a more accurate assessment of environmental pollution damage taking into account the time factor by application of the discounting (present value) technique. The time factor is also accommodated in assessing other economic indicators. Therefore, the total costs for individual segments and the optimum field pipeline route solution take into account the time factor.

It should be noted that the calculations are based on fuzzy estimates of cost levels reflecting the high uncertainty over the probabilistic damage (risk) linked to environmental pollution and costs related to compensatory projects and payments to local populations. Fuzzy estimates of damage have already been approached, e.g. see (Pislaru et al. 2013). This paper considerably extends the scope of application of fuzzy estimates to all costs related to the construction and operation of an oil pipeline.

The fundamentally new tool for making the conclusive choice of the field pipeline route is the approach proposed in the paper for calculating confidence levels for the variation range of the total costs between the minimum to the maximum value. The chart of the change in confidence levels represents not only total costs of pipeline construction and operation including environmental and compensatory spending but also the identified optimum routes.

The proposed approach was used for planning field pipelines in hydrocarbon production in the Arctic zone conditions.

\section{Conclusions}

The set problem of identifying an optimum pipeline route is different from the practical applications and known theoretical approaches used for similar problems in that the cost calculations operated take into account fuzzy estimates of environmental pollution damage and compensation payments to the local population in the region. The performed analysis of a wide range of approaches to pipeline route optimization helped to select the most practical method for software implementation and addressing middle- to large- dimension problems employing matrix operations, the Shimbel-Otterman method. The results of the conducted calculations prove the practical feasibility of the application of the described approach of this paper to address a wide range of problems concerning calculations of optimum pipeline routes to prevent conflicts with the local population.

\section{References}

Guri, A.; Guri, S.; Aliu, A.; Lubonja O. 2013. The Impact of Oil Development Activities on Environment and Sustainable evelopment in Fier Area, Albania. Academic Journal of Interdisciplinary Studies 2(9): 626-634. http://doi.org/10.5901/AJIS.2013.V2N9P626

Nriagu, J.; Udofia, E.A.; Ekong, I.; Ebuk, G. 2016. Health Risks Associated with Oil Pollution in the Niger Delta, Nigeria. International Journal of Environmental Research and Public Health 13(3): 346. http://doi.org/10.3390/ijerph13030346

O'Faircheallaigh, C. 2009. Public participation and environmental impact assessment: Purposes, implications, and lessons for public policy making. Environmental Impact Assessment Review 30(1): 19-27. http://doi.org/10.1016/j.eiar.2009.05.001 


\section{ENTREPRENEURSHIP AND SUSTAINABILITY ISSUES}

ISSN 2345-0282 (online) http://jssidoi.org/jesi/ 2019 Volume 7 Number 1 (September) http://doi.org/10.9770/jesi.2019.7.1(55)

Porfiryev, B. N.; Tulupov, A.S. 2017. Environmental Hazard Assessment and Forecast of Economic Damage from Industrial Accidents. Studies on Russian Economic Development 6: 600-607. http://doi.org/10.1134/S1075700717060107

Fetisov, V.G.; Nikolaev, A.K.; Lykov, U.V. 2016. Prediction of oil loss as a result accident branched pipeline oil. Slovak international scientific journal 1(1): 73-82. http://sis-journal.com/wp-content/uploads/2016/12/Sis-journal_1.pdf

Uzhga-Rebrov, O.; Kuleshova, G. 2015. Operating with Fuzzy Probability Estimates in Decision Making Processes with Risk. Information Technology and Management Science 18: 102-114. http://doi.org/10.1515/itms-2015-0017

Tulupov, A.S. 2017. Compensation for environmental damage in the economy of mining. Gornyi Zhurnal 8: 61-65. http://doi.org/10.17580/gzh.2017.08.11

Novoselova, I. Y.; Novoselov, A. L. 2016. Estimation of Accumulated Environmental Damage: Methods and Experience. Journal of Environmental Management and Tourism, 4(16): 619-624. http://doi.org/10.14505/jemt.v7.4(16).08

Akhtar, T.; Mahmood Baig, M. 2016. New artistic approach for shortest path by using swarm intelligence. Sci.Int.(Lahore) 28(2): 10671070. http://www.sci-int.com/pdf/6787553671\%20a\%201067-1070\%20Talha\%20Shahid--PHY--REVIEWED--15-2-16.pdf

Schrijver, A. 2012. On the History of the Shortest Path Problem. Documenta Mathematica Extra Volume ISMP: $155-167$. https://www.math.uni-bielefeld.de/documenta/vol-ismp/32_schrijver-alexander-sp.pdf

Shvetsova, O.A.; Rodionova, E.A.; Epstein, M. Z. 2018. Evaluation of investment projects under uncertainty: multi-criteria approach using interval data. Entrepreneurship and Sustainability Issues, 5(4): 914-928. http://doi.org/10.9770/jesi.2018.5.4(15)

Ahmed, F.; Kilic, K. 2019. Fuzzy Analytic Hierarchy Process: A performance analysis of various algorithms. Fuzzy Sets and Systems, 362: 110-128. http://doi.org/10.1016/j.fss.2018.08.009

Mazarbhuiya, F.A. 2016. Finding standard deviation of a fuzzy number. International Journal of Research - GRANTHAALAYAH 4(1): 63-69. http://granthaalayah.com/Articles/Vol4Iss1/08 IJRG16 A01 11.pdf

Novoselov, A.; Potravny, I.; Novoselova, I.; Gassiy, V. 2016. Conflicts Management in Natural Resources Use and Environment Protection on the Regional Level. Journal of Environmental Management and Tourism 7(3): 407-415. http://doi.org/10.14505/jemt.v7.3(15).06

Chhabra, J.P.S.; Hasik, V.; Bilec, M.M.; Warn, G.P. 2018. Probabilistic Assessment of the Life-Cycle Environmental Performance and Functional Life of Buildings due to Seismic Events. Journal of Architectural Engineering 24(1). http://doi.org/10.1061/(ASCE)AE.1943-5568.0000284

Pislaru, M.; Trandabat, A.F.; Trandabat, D. 2013. Assessment of Corporate Environmental Performance Based on Fuzzy Approach. APCBEE Procedia 5: 368-372. http://doi.org/10.1016/j.apcbee.2013.05.063 
ENTREPRENEURSHIP AND SUSTAINABILITY ISSUES

ISSN 2345-0282 (online) http://jssidoi.org/jesi/

2019 Volume 7 Number 1 (September)

http://doi.org/10.9770/jesi.2019.7.1(55)

\section{Andrey NOVOSELOV}

ORCID ID: 0000-0003-1495-4836

Irina NOVOSELOVA

ORCID ID: 0000-0002-5054-0676

Ruslan ALIYEV ORCID

ID: 0000-0003-2258-3588

Andrey AVRAMENKO

ORCID ID: 0000-0001-5862-5466

Register for an ORCID ID:

https://orcid.org/register

Copyright (C) 2019 by author(s) and VsI Entrepreneurship and Sustainability Center

This work is licensed under the Creative Commons Attribution International License (CC BY).

http://creativecommons.org/licenses/by/4.0/

(c) †) Open Access 